\title{
COMUNICAÇÃO EDUCATIVA DO ENFERMEIRO NA PROMOÇÃO DA SAÚDE SEXUAL DO ESCOLAR
}

Maria Alice F. Colli Oliveira * Sônia Maria Villela Bueno **

OLIVEIRA, M.A.F.C.; BUENO, S.M.V. Comunicação educativa do enfermeiro na promoção da saúde sexual escolar Rev.latino-am.enfermagem, Ribeirão Preto, v. 5, n. 3, p. 71-81, julho 1997.

A escola é o espaço crucial para o desenvolvimento de conhecimentos e habilidades junto aos seus integrantes e comunidade, visando a garantia de mudanças de comportamento. E, particularmente, por existir carência de informações aos alunos sobre sexualidade e DST-HIV/AIDS, dificultando resolução de seus problemas, procuramos pesquisar escolares das 3 séries do $2^{\circ}$ grau, de uma cidade próxima de Ribeirão Preto - SP. Visamos identificar seus problemas, executando e avaliando ações educativas conjuntas sobre os problemas levantados. Os resultados evidenciaram que esses alunos relacionam a AIDS à fatalidade e temeridade, talvez influenciados pelas mensagens emitidas na $1^{a}$ década da história desta doença, enquanto hoje, a tendência é trabalhar conhecimentos atualizados e habilidades voltados à não discriminação e à solidariedade, em razão da existência já eminente do doente / doença, na sociedade. Conceituam a AIDS como doença do sexo e prevenível, porém revelando desinformação em outros aspectos básicos da temática, justificando necessidade de ações educativas. Portanto, sugerimos que os enfermeiros trabalhem efetivamente esta questão no cotidiano do escolar, tendo em vista sua saúde sexual e integral.

UNITERMOS: comunicação em enfermagem, educação para a saúde, escolares x DST-HIV/AIDS, saúde sexual

\section{INTRODUÇÃO}

Muitos dos aspectos ligados à sexualidade e Doenças Sexualmente Transmissíveis/ Síndrome da Imunodeficiência Humana (DST/AIDS), vêm sendo trabalhados, no social, principalmente pelos agentes da Educação e da Saúde. Ainda que timidamente, o processo educativo direciona para a desmistificação do sexo ligado a conotação de feio, ruim, sujo e pecaminoso, caminhando também à uma orientação para a compreensão dos ganhos e perdas da vida, tendo em vista, a negociação, para a conquista de uma vida melhor. A não reversão destes problemas têm significado verdadeiros entraves na educação da criança e do adolescente, dificultando assim, o avanço da sua saúde integral e, particularmente, da sua saúde sexual, tanto do aspecto individual quanto coletivo, quando na verdade, devesse existir orientação adequada à adoção de hábitos e estilo de vida, saudáveis e responsáveis ${ }^{1,2,3,4}$.

O despreparo das pessoas em geral, de pais e profissionais para trabalharem estas questões consigo mesmo e com o contingente infanto-juvenil no seu cotidiano e em sua contextualidade, representa, certamente, o atravancamento das possibilidades de avanço para a saúde e a melhoria da qualidade de vida pessoal e comunitária, prejudicando, assim, o exercício da cidadania.

A desinformação, por sua vez, tem peso significativo neste processo, favorecendo, consideravelmente, a vulnerabilidade aos riscos de contaminação, na aquisição de doenças, sobretudo as DST/AIDS, como também, prejudica o enfrentamento de muitos outros problemas, nesta área. Esta situação torna-se mais grave na vida das crianças e dos jovens, quando na realidade, além da falta de conhecimentos específicos sobre estas questões, ainda pesam sobre eles, a inabilidade em trabalharem estes aspectos, com o surgimento de dificuldades desta ordem, no seu cotidiano. E além do mais, entendemos que, especialmente os jovens, por estarem muitos deles, já vivenciando suas práticas sexuais, de forma ativa, acabam passando por circunstâncias complexas, que a sua própria

\footnotetext{
* Enfermeira, mestranda em Enfermagem Psiquiátrica da Escola de Enfermagem de Ribeirão Preto da Universidade de São Paulo ** Professora Doutora do Departamento de Enfermagem Psiquiátrica e Ciências Humanas da Escola de Enfermagem de Ribeirão Preto da Universidade de São Paulo (Pedagoga)

- Este estudo faz parte de projeto mais amplo desenvolvido no Programa de Pós-Graduação do Departamento de Enfermagem Psiquiátrica e Ciências Humanas da Escola de Enfermagem de Ribeirão Preto da Universidade de São Paulo
} 
contextualidade os expõe, necessitando assim, de um trabalho educativo efetivo, visando atender esta demanda ${ }^{1,5}$.

Não obstante, a comunicação de massa, isto é, televisiva (TV, vídeos) ou escrita e falada (rádio, jornal, revista, etc), muito tem contribuído, na emissão de mensagens sobre estas questões. Desta maneira, a mídia tem reportado frequientemente, notícias sobre as Doenças Sexualmente Transmissíveis, Vírus da Imunideficiência Humana e Síndrome da Imunodeficiência Humana (DSTHIV/AIDS). Todavia, muitas destas mensagens transmitidas, embora importantes, têm trazido à tona, dados mais quantitativos que qualitativos. Tem divulgado mais números do que travado discussões e tecendo reflexões e comentários sobre os mesmos. Quando devessem destacar mais conhecimentos específicos, avanços e habilidades sobre o assunto, visando, assim, a garantia de uma educação para a saúde coletiva mais efetiva, devido ao seu poder persuasivo de divulgação, de formação e de transformacão, atingindo assim, índices consideráveis da população, ao mesmo tempo. Esses veículos de comunicação influenciam de forma significante, na mudança de comportamento das pessoas, em geral, de forma acelerada.

Por outro lado, a escola significa um local importante para se trabalhar conhecimentos, habilidades e mudanças de comportamentos. Ela representa um contexto propício e adequado para o desenvolvimento de ações educativas, atuando nas diferentes áreas do saber humano. E, neste sentido, mais do que nunca, há de se investir nas questões da sexualidade e das DST-HIV/ AIDS, entre outras, desmistificando, porém, preconceitos e tabus existentes, bem como crenças, valores e mitos esteriotipados na educação das pessoas, ao longo dos tempos. Isto exige, portanto, estratégias pedagógicas apropriadas, visando a integração da família e da comunidade neste processo $6,7,8$

Nos últimos tempos, os escolares têm bombardeado seus professores ou similares, à busca de informações e esclarecimentos sobre as questões da sexualidade e do sexo frente às DST-AIDS entre outros problemas correlatos. Por sua vez, muitas escolas tem buscado a equipe multidisciplinar para dar assessoria a estes programas. Embora havendo importância e avanço neste intento escolar, ainda há muito o que se fazer.

Baseando-se nestes referenciais, fundamentamos a justificativa do presente estudo, compreendendo que a escola é o espaço crucial para se trabalhar esta questão, pois há uma demanda crescente de escolares, à busca de uma educação que venha propiciar informação, discussão e solução para seus problemas. Neste contexto, a atuação do enfermeiro como educador e assessor é de considerável relevância, contando com o apoio da interdisciplinaridade.
Pensando nisto, procuramos desenvolver a presente investigação partindo da pesquisa à ação, tendo em vista o papel do enfermeiro, neste processo comunicativo, em Educação para a Saúde Sexual do escolar.

\section{OBJETIVOS}

Levando-se em consideração o conhecimento das dificuldades que os escolares têm vivenciado, em relação às questões que permeiam a sexualidade/DST-AIDS na sua contextualidade, procuramos, no presente estudo, levantar os seguintes objetivos:

1. Identificar os reais problemas dos jovens escolares pesquisados;

2. Planejar, executar e avaliar um programa educativo voltado para as dificuldades encontradas, em ação conjunta com os alunos trabalhados.

\section{METODOLOGIA}

Para o desenvolvimento deste estudo, já nos encontrávamos inseridas no contexto escolar trabalhado (Escolas Estaduais de Guatapará, município próximo de Ribeirão Preto - SP, constituída de cerca de 5.000 habitantes). De início, visamos observar atentamente, as dificuldades enfrentadas pelos jovens daquela comunidade. Para tanto, passamos a ter participação efetiva com eles, garantindo, assim, a confiabilidade deles, procurando criar um vínculo de respeito e responsabilidade entre alunos $\mathrm{x}$ pesquisadoras $\mathrm{x}$ professores $\mathrm{x}$ família $\mathrm{x}$ comunidade.

A seguir, levantamos as necessidades deles, por escrito, culminando com a exposição de problemas emergentes, relacionados à Educação para a sexualidade e DST/AIDS.

Para tanto, utilizamos a observação e procedemos com a aplicação de entrevistas individuais e coletivas, realizadas através de instrumentos, constando de questões norteadoras, que pudessem facilitar a expressão de dificuldades, emitidas pelos sujeitos pesquisados. A coleta destes dados durou o semestre todo, permitindo a cada um, exposição de suas dúvidas. Uma vez elaborado o levantamento das matrizes destes dados emitidos, procuramos planejar com os escolares, com apoio dos professores e dos pais, o conteúdo do programa, através de oficinas pedagógicas, o qual foi executado e avaliado, com assessoria de uma equipe multidisciplinar, visando atender aos objetivos propostos.

Desta forma, o programa educativo desenvolvido, teve como fases e etapas: 
1) Levantamento das necessidades junto dos escolares, visando atendê-las;

2) Planejamento do programa educativo, tendo-se em vista as prioridades e emergências detectadas na coleta dos dados:

3) Execução do conteúdo programático, através de palestras e oficinas sobre os temas planejados, baseandose em oficinas pedagógicas de vivências preconizadas pelo Ministério da Saúde, trabalhando-se temas como: conceito sobre sexualidade e sexo seguro, DST, AIDS, solidariedade, discriminação, etc.

Os temas trabalhados foram apresentados, de forma contextualizada, não apresentando apenas aspecto puramente biológico.

O conteúdo programático foi o seguinte:

I. Conceitos sobre sexualidade, sexo e sexo seguro.

II. Anatomia e fisiologia do corpo humano

- órgãos genitais masculinos e femininos (internos e externos)

- ciclo menstrual, polução noturna

- ovulação

- fecundação

- gravidez (fases) e aborto

- métodos anticoncepcionais

III. Reprodução Humana ( fixação e memorização )

IV. Comunicação, interação social, familiar e comunitária ( tipos de grupos )

V. DST : sífilis, gonorréia, cancro mole, condiloma acuminado, herpes genital, uretrite gonorréica, candidíase e etc.

VI. AIDS : conceito, prevenção e controle, discriminação $\mathrm{x}$ solidariedade

VII. Drogas: reforçando perdas e ganhos da vida e necessidade da procura da compreensão dos elementos fundamentais da saúde integral tanto ao nível individual quanto coletivo, influência grupal e etc.

4) Avaliação do programa educativo (ver anexo I) através das questões:

A - Vivências, dramatizações e teatro/palestras e discussões/debates.

B - Instrumento avaliativo com questões como:

a - O que você achou do programa educativo?

$\mathrm{b}$ - O que você mais gostou?

c - O que você menos gostou?

d - Quais as dúvidas que ainda permaneceram em você? e - Sugestões.

C - Foram deixadas caixas (tipo urna) em cada classe, para que os alunos, após receberem o programa educativo, pudessem deixar por escrito, dúvidas que fossem surgindo, com sugestões para possíveis trabalhos, em outro momento, com os profissionais de saúde e da educação, sobre os temas propostos.

Foram trabalhados também materiais didáticos apropriados (cartilhas educativas, cartazes, folhetos, panfletos, etc), para facilitar o processo ensinoaprendizagem, tendo em vista, o conhecimento e as habilidades específicas sobre a temática central, para a garantia da mudança de comportamentos da população estudada.

Neste sentido, fundamentamos a importância desta pedagogia, levando-se em consideração, os preceitos éticos e morais para a valorização da escola centrada no aluno, compreendendo-o enquanto agente ativo, crítico e reflexivo, sujeito à mudança e transformação, bem como, multiplicador destas ações aos seus pares. Consideramos, ainda, os referenciais teóricos preconizados pela Organização Mundial de Saúde (OMS), resgatando o sentido da valorização da qualidade de vida, da visão totalizadora e contextualizada do indivíduo e do exercício à cidadania.

Para o estudo dos resultados, utilizamos o procedimento trabalhado por Giorgi, tendo em vista, a análise por categorização, para facilitar a compreensão e interpretação dos dados emitidos, trabalhado por Vietta \& Bueno apud BUENO ${ }^{3}$.

\section{RESULTADOS E DISCUSSÕES}

Estaremos trabalhando aqui, os resultados seguidos das discussões. Inicialmente, serão apresentados os dados de identificação, no sentido de caracterizar a população trabalhada. Posteriormente, serão demonstrados e analisados os dados referentes às questões levantadas, que nortearam o presente estudo.

Conforme o Quadro 1, os 77 alunos do $2^{\circ}$ grau pesquisados, das escolas da rede estadual de ensino de Guatapará (município próximo à Ribeirão Preto), são assim identificados: 21,26 e 30, respectivamente, nas $1^{\text {as }}, 2^{\text {as }}$ e $3^{\text {as }}$ séries. Desses, $56 \%$ são do sexo masculino, a faixa etária de idade varia, de 15 a 57 anos, predominando entre 16 a 24, e 78\% são solteiros.

No que se refere à questão : "Para você, qual o conceito de AIDS", a Tabela 1, evidencia que a maioria dos estudantes investigados, conceitua AIDS como sendo: doença do sexo (53\%); incurável (26\%); causada por um vírus (21\%); que facilita outras doenças (13\%); perigosa / que tortura (12\%); síndrome de imunodeficiência adquirida (10\%); de fácil transmissão e prevenção (8\%); doença do século (3\%) e previnível por camisinha (1\%). Em relação ao conceito da AIDS como uma doença transmissível, a maioria (53\%) acredita ser através do sexo (DST/venérea),embora $43 \%$ enfocassem também a via sangüínea como meio de contaminação. Demonstram adequadamente, embora em menor número, que a AIDS não é transmitida pelo beijo ou aperto de mão.

Portanto, pudemos evidenciar que a maioria dos 
sujeitos estudados emite o conceito de AIDS enquanto doença relacionada, principalmente, ao sexo. enquanto que $1 / 4$ percebem-na como incurável/fatal, revelando conhecimento relativo à semântica desta doença.

O sentido da moléstia ligado à terminalidade revela a influência das mensagens emitidas, bem como, da possível proximidade com parentes ou amigos, acometidos pelo HIV/AIDS.

No começo da epidemia, a educação era voltada ao temor da AIDS. Desta forma, havia necessidade de chamar a atenção da população para a situação de fatalidade eminente. Este fato permanece atualmente, por não existir ainda vacina para a prevenção e tão pouco, medicação para o combate do HIV. O processo educativo voltado para o medo, marcou a primeira década da doença, quando se pensava em atingir o povo, de imediato, alertando a todos contra o perigo da morte, enquanto estratégia de "choque". Todavia, hoje, por já existir número considerável de casos de HIV/AIDS na sociedade, as pessoas passaram a enfrentar o preconceito, além do temor já existente, em relação ao doente e à doença. Essa realidade tornou-se evidente na comunidade em geral e obviamente, passou a ser vivenciada também, dentro ou próximo do ambiente familiar. Desta maneira, os últimos tempos passaram a exigir uma pedagogia apropriada, voltada fundamentalmente, para a prevenção, para a não discriminação e para a solidariedade humana. Isto implica em considerar, de forma relevante, os preceitos preconizados pela Organização Mundial da Saúde (OMS), no sentido de trabalhar a valorização da vida, tendo em vista, a busca de melhores condições para a prevenção, manutenção e restauração da saúde, dentro de uma visão totalizadora do ser humano e do resgate à cidadania $^{2,5}$

QUADRO 1 - Distribuição numérica e percentual referente aos dados de identificação dos alunos do segundo grau pesquisados, segundo sexo, faixa etária e estado civil

\begin{tabular}{|c|c|c|c|c|c|}
\hline \multirow[t]{2}{*}{ IDEN TIFICAÇÃO } & \multicolumn{3}{|c|}{ SÉRIE } & \multirow{2}{*}{$\begin{array}{c}\text { TOTAL } \\
\left(\mathrm{N}^{\circ}\right)\end{array}$} & \multirow{2}{*}{$\begin{array}{c}\text { TOTAL } \\
(\%)\end{array}$} \\
\hline & $1^{2}$ & $2^{2}$ & $3^{2}$ & & \\
\hline \multicolumn{6}{|l|}{ SEXO } \\
\hline masculino & 10 & 13 & 20 & 43 & 56 \\
\hline feminino & 11 & 13 & 10 & 34 & 44 \\
\hline total & 21 & 26 & 30 & 77 & 100 \\
\hline \multicolumn{6}{|l|}{ FAIXA ETARIA } \\
\hline$<=15$ & 09 & 00 & 00 & 09 & 12 \\
\hline 16 a 18 & 11 & 12 & 11 & 34 & 44 \\
\hline 19 a 21 & 01 & 00 & 04 & 05 & 6 \\
\hline 22 a 24 & 00 & 02 & 07 & 09 & 12 \\
\hline 25 a 27 & 00 & 01 & 01 & 02 & 3 \\
\hline 28 a 30 & 00 & 02 & 00 & 02 & 3 \\
\hline$>=31$ & 00 & 02 & 01 & 03 & 4 \\
\hline em branco & 00 & 07 & 06 & 13 & 17 \\
\hline total & 21 & 26 & 30 & 77 & 100 \\
\hline \multicolumn{6}{|l|}{ ESTADO CVIL } \\
\hline casado & 00 & 04 & 02 & 06 & 8 \\
\hline solteiro & 21 & 19 & 20 & 60 & 78 \\
\hline amasiado & 00 & 00 & 02 & 02 & 3 \\
\hline em branco & 00 & 03 & 06 & 09 & 12 \\
\hline total & 21 & 26 & 30 & 77 & 100 \\
\hline
\end{tabular}


TABELA 1 - Distribuição numérica e percentual das respostas emitidas pelos alunos do segundo grau pesquisados sobre a questão: "Para você, qual o conceito de AIDS?"

\begin{tabular}{|c|c|c|c|c|c|}
\hline RESPOSTAS & & SÉRIE & & TOTAL* & TOTAL \\
\hline AIDS E: & $1^{\mathrm{a}}$ & $2^{\mathrm{a}}$ & $3^{\mathrm{a}}$ & $\mathrm{N}^{\circ}$ & $\%$ \\
\hline
\end{tabular}

UMA DOENCA

\begin{tabular}{|c|c|c|c|c|c|}
\hline do sexo & 14 & 12 & 15 & 41 & 53 \\
\hline incurável/fatal & 07 & 01 & 12 & 20 & 26 \\
\hline causada por vírus HIV & 03 & 06 & 07 & 16 & 21 \\
\hline que facilita outras doenças & 04 & 03 & 03 & 10 & 13 \\
\hline que causa perigo/tortura & 04 & 04 & 01 & 09 & 12 \\
\hline Sind. Imunod.Adquirida & 00 & 00 & 08 & 08 & 10 \\
\hline de fácil transmissão/contágio & 02 & 03 & 01 & 06 & 08 \\
\hline que exige cuidado/prevenção & 00 & 06 & 00 & 06 & 08 \\
\hline do século & 00 & 00 & 02 & 02 & 03 \\
\hline prevenida por camisinha & 01 & 00 & 00 & 01 & 01 \\
\hline
\end{tabular}

\section{TRANSMITIDA POR}

\begin{tabular}{|c|c|c|c|c|c|}
\hline $\begin{array}{l}\text { DST/venérea } \\
\text { sangue }\end{array}$ & 14 & 12 & 15 & 41 & 53 \\
\hline transfus ão/droga/seringa/agulha & 08 & 10 & 15 & 33 & 43 \\
\hline
\end{tabular}

\section{NAO TRANSMITIDA POR}

$\begin{array}{llllll}\text { beijo } & 00 & 01 & 00 & 01 & 01 \\ \text { aperto de mão } & 00 & 01 & 00 & 01 & 01\end{array}$

* houve mais de uma resposta para alguns sujeitos. A porcentagem foi calculada pelo total da população pesquisada, isto é, 77 alunos ( 21 da $1^{\mathrm{a}}$ série; 26 da $2^{\mathrm{a}}$ e 30 da $3^{\mathrm{a}}$ )

No que tange à questão: “O que você pensa sobre a AIDS?", a Tabela 2 evidencia que os jovens relacionam-na a sentimentos negativos ligando-a a: fatalidade (36\%); crueldade (21\%); medo (12\%), assim como, causadora de destruição de relacionamentos (4\%). Em menor escala, surgem outras formas de pensar a AIDS, evidenciando a sua incidência, por falta de prevenção e conscientização/informação (6\%), a problemas epidemiológicos (controle populacional, $4 \%$; alastramento, 4\%) e sendo prejudicial à saúde das pessoas porque ela contamina $(6 \%)$.
Em outros, surgiram respostas isoladas como: não pensa em nada (5\%); doença do século (4\%)e que exige atenção especial(4\%), entre outras, enquanto que $21 \%$, deixaram de responder esta questão.

A partir destes referenciais, pudemos depreender que a maioria desses jovens tem uma idéia da AIDS voltada para os aspectos negativos da doença, relacionando-a fundamentalmente, à morte e ao medo, em razão da própria fatalidade que esta moléstia ocasiona. 
TABELA 2 - Distribuição numérica e percentual das respostas emitidas pelos alunos do segundo grau pesquisados sobre a questão: “O que você pensa sobre a AIDS?"

\begin{tabular}{|c|c|c|c|c|c|}
\hline \multirow{2}{*}{$\begin{array}{l}\text { RESPOSTAS: } \\
\text { Pensa ser a AIDS: }\end{array}$} & \multicolumn{3}{|c|}{ SÉRIE } & \multirow{2}{*}{$\begin{array}{c}\text { TOTAL* } \\
N^{\circ}\end{array}$} & \multirow{2}{*}{$\begin{array}{l}\text { TOTAL } \\
\%\end{array}$} \\
\hline & $1^{\mathrm{a}}$ & $2^{\mathrm{a}}$ & $3^{\mathrm{a}}$ & & \\
\hline \multicolumn{6}{|l|}{ doença relacionadaa sentimentos negativos } \\
\hline fatalidade/morte/destruição & 7 & 4 & 17 & 28 & 36 \\
\hline crueldade/perigo/gravidade & 5 & 5 & 6 & 16 & 21 \\
\hline medo/terror/horror/temor & 4 & 1 & 4 & 9 & 12 \\
\hline destruição de relacionamentos & 2 & 0 & 1 & 3 & 4 \\
\hline \multicolumn{6}{|l|}{ doença causada por desinformação } \\
\hline falta de prevenção & 8 & 5 & 5 & 18 & 23 \\
\hline falta de conscientização/informação & 2 & 1 & 2 & 5 & 6 \\
\hline \multicolumn{6}{|l|}{ doença ligada a problema epidemiológico } \\
\hline controle populacional & 0 & 2 & 1 & 3 & 4 \\
\hline alastramento/praga & 2 & 0 & 1 & 3 & 4 \\
\hline problema social & 0 & 0 & 1 & 1 & 1 \\
\hline \multicolumn{6}{|l|}{ doença que prejudica a saúde porque } \\
\hline pode contaminar qualquer pessoa/transmitir & 0 & 1 & 4 & 5 & 6 \\
\hline diminuir a imunidade & 0 & 1 & 0 & 1 & 1 \\
\hline é transmitida sexualmente & 1 & 0 & 0 & 1 & 1 \\
\hline \multicolumn{6}{|l|}{ outros } \\
\hline não pensa nada & 2 & 1 & 1 & 4 & 5 \\
\hline doença do século & 0 & 0 & 3 & 3 & 4 \\
\hline cuidados médicos/pesquisa/prevençao de drogas & 1 & 2 & 0 & 3 & 4 \\
\hline doença que pode ser evitada & 0 & 0 & 2 & 2 & 3 \\
\hline doença que não deveria existir no mundo & 0 & 2 & 0 & 2 & 3 \\
\hline doença que pode acontecer com qualquer um & 1 & 0 & 0 & 1 & 1 \\
\hline doença que está na hora de acabar & 0 & 0 & 1 & 1 & 1 \\
\hline em branco & 5 & 9 & 2 & 16 & 21 \\
\hline
\end{tabular}

* Houve mais de uma resposta para alguns sujeitos. A porcentagem foi calculada pelo total da população pesquisada, isto é, 77 alunos ( 21 da $1^{\mathrm{a}}$ série; 26 da $2^{\mathrm{a}}$ série e 30 da $3^{\mathrm{a}}$ série)

Contudo, não podemos esquecer que embora o HIV/AIDS possa propiciar a fatalidade humana, entre outras graves circunstâncias em que a doença venha nos confrontar, ela apresenta um aspecto fundamental e importante para o presente estudo e para a vida das pessoas - é o seu aspecto preventivo. E, em sendo previnível, todas as pessoas podem evitar este problema, à busca da educação, através da orientação e da informação efetivas, visando a promoção da sua saúde sexual e por, conseguinte, contribuindo para a sua saúde integral do indivíduo e da sua coletividade.

Na questão: "Como devemos evitar/prevenir a AIDS?", pudemos constatar que a maioria dos escolares pesquisados, acredita ser a educação a forma mais efetiva para o combate da doença, conforme demonstra a Tabela 3. O uso de camisinha foi citado por $84 \%$ deles e $51 \%$ referiram as agulhas e seringas descartáveis. Em ordem decrescente, surgiram outras respostas para a prevenção, como: redução do número de parceiros , devendo serem esses conhecidos; a não utilização de drogas; prevenção/ cuidados, entre outros. Assim, pudemos detectar que a maioria deles reconhece a importância da prevenção como forma efetiva de se evitar a AIDS, afirmando haver diversas maneiras para prevenir-se, mencionando, como exemplo, o uso de preservativos. 
TABELA 3 - Distribuição numérica e percentual das respostas emitidas pelos alunos do segundo grau pesquisados sobre a questão: “Como devemos evitar a AIDS?

\begin{tabular}{|c|c|c|c|c|c|}
\hline RESPOSTAS & & SERIE & & TOTAL* & TOTAL \\
\hline PREVENÇÃO DA AIDS ATRAVÉS DE & $1^{\mathrm{a}}$ & $2^{\mathrm{a}}$ & $3^{\mathrm{a}}$ & $\mathrm{N}^{\circ}$ & $\%$ \\
\hline \multicolumn{6}{|l|}{ vias de prevenção } \\
\hline uso de preservativos/camisinha & 17 & 23 & 25 & 65 & 84 \\
\hline uso de seringas descartáveis & 11 & 12 & 16 & 39 & 51 \\
\hline redução do $n^{\circ}$ de parceiros/conhecendo-os & 5 & 7 & 11 & 23 & 30 \\
\hline não uso de drogas & 7 & 3 & 12 & 22 & 29 \\
\hline prevenção/cuidados & 1 & 2 & 5 & 8 & 11 \\
\hline cuidado com transfusão sangüinea & 5 & 0 & 2 & 7 & 9 \\
\hline esterilização adequada de materiais & 1 & 0 & 5 & 6 & 8 \\
\hline evitar contato com portador & 2 & 0 & 2 & 4 & 5 \\
\hline abstinência/não fazer sexo & 1 & 0 & 0 & 1 & 1 \\
\hline \multicolumn{6}{|l|}{ outros } \\
\hline evitar beijo & 0 & 1 & 1 & 2 & 3 \\
\hline selecionar doadores de sangue & 0 & 2 & 0 & 2 & 3 \\
\hline parar de bagunçar & 0 & 1 & 0 & 1 & 1 \\
\hline conhecer o tipo de sangue do parceiro & 0 & 1 & 0 & 1 & 1 \\
\hline evitar roupas de pessoas contaminadas & 0 & 1 & 0 & 1 & 1 \\
\hline em branco & 0 & 1 & 1 & 2 & 3 \\
\hline
\end{tabular}

* Houve mais de uma resposta para alguns sujeitos. A porcentagem foi calculada pelo total da população pesquisada, isto é, 77 alunos ( 21 da $1^{\mathrm{a}}$ série; 26 da $2^{\mathrm{a}}$ série e 30 para os da $3^{\mathrm{a}}$ série)

A prevenção da AIDS, principalmente através da utilização da camisinha (condon ou preservativo de borracha/látex), vem sendo, atualmente, muito divulgada nas campanhas educativas de massa. Não obstante, há outras formas que devem ser lembradas, tais como: abstinência, auto-prazer, postergação do sexo; monogamia com diálogo aberto; evitar promiscuidade e troca de parceiros, entre outras. Ainda assim, alerta-se para não descartar o uso de preservativos em qualquer situação sexual de parceria.

No presente estudo, há indícios de desinformação por alguns, diante desta questão, quando afirmam que pode-se evitar esta doença, ao: "conhecer o tipo de sangue do parceiro"; "evitar o beijo" e "evitar usar roupas de pessoas contaminadas" como forma de prevenção.

Outros dados nos despertam certa preocupação, pois que há necessidade de se trabalhar com eles, a negociação para o sexo seguro, com respeito e responsabilidade, além de que as vias principais de transmissão são por: via sexual (através do semen e secreção vaginal) e sangüínea. E nesta guerra, a mulher vem perdendo consideravelmente para o homem, o que é lastimável, uma vez que, se ela estiver contaminada e grávida, poderá contaminar seu filho por via vertical, por sangue, secreções vaginais e leite materno.

$\mathrm{Na}$ questão: "A que você atribui o aparecimento da AIDS no mundo?" os escolares estudados respondem, conforme demonstra a Tabela 4, que ela surgiu através do macaco (da África, por sua carne, sexo, $17 \%) ; 14 \%$ acreditam no seu aparecimento devido ao sexo (abuso sexual, promiscuidade/ prostituição, contato sexual) e 5\%, devido às drogas. Outras atribuições foram dadas como: para controle dos abusos sexuais (3\%) e prazeres do mundo (5\%); falta de prevenção / cuidados (4\%); vírus criados por cientistas em laboratórios (6\%); final do mundo (3\%), alerta à humanidade (1\%), etc. Dos pesquisados, $30 \%$ não tem idéia do porque do aparecimento da AIDS, enquanto 27\%, deixaram a questão sem resposta. Surgiram, ainda, outras categorias com atribuições diferentes ao aparecimento da doença, como: provocada pelo sexo e uso de drogas, como forma de freio à sociedade pelo abuso sexual (promiscuidade e estupro) e aos índices elevados de uso de drogas injetáveis, nos nossos dias. Esses alunos, ainda, atribuíram a falta de prevenção como causa do surgimento da AIDS no mundo. 
TABELA 4 - Distribuição numérica e percentual das respostas emitidas por alunos do $2^{\circ}$ grau pesquisados sobre a questão: "A que você atribui o aparecimento das AIDS?"

\begin{tabular}{|c|c|c|c|c|c|}
\hline \multirow{2}{*}{$\begin{array}{l}\text { RESPOSTAS } \\
\text { ATRIBUIÇÕ̃ES DA AIDS NO MUNDO }\end{array}$} & \multicolumn{3}{|c|}{ SÉRIE } & \multirow{2}{*}{$\begin{array}{c}\text { TOTAL* } \\
\mathrm{N}^{\circ}\end{array}$} & \multirow{2}{*}{$\begin{array}{c}\text { TOTAL } \\
\%\end{array}$} \\
\hline & $1^{\mathrm{a}}$ & $2^{\mathrm{a}}$ & $3^{\mathrm{a}}$ & & \\
\hline \multicolumn{6}{|l|}{ surgimento através do } \\
\hline macaco (carne/sexo/Africa) & 0 & 9 & 4 & 13 & 17 \\
\hline \multicolumn{6}{|l|}{ sexo } \\
\hline prostituição/promiscuidade/variedade de parceiros & 2 & 0 & 1 & 3 & 4 \\
\hline abuso sexual & 2 & 0 & 0 & 2 & 3 \\
\hline contato sexual & 0 & 0 & 1 & 1 & 1 \\
\hline \multicolumn{6}{|l|}{ surgimento para controle/freio } \\
\hline pelos prazeres do mundo e drogas & 3 & 1 & 0 & 4 & 5 \\
\hline pelos abusos sexuais & 2 & 0 & 0 & 2 & 3 \\
\hline \multicolumn{6}{|l|}{ surgimento por falta de } \\
\hline prevenção/cuidado & 2 & 1 & 0 & 3 & 4 \\
\hline \multicolumn{6}{|l|}{ surgimento de outras hipóteses } \\
\hline criado por cientistas (laboratório) & 0 & 2 & 3 & 5 & 6 \\
\hline final de mundo & 2 & 0 & 0 & 2 & 3 \\
\hline $\begin{array}{l}\text { criado HIV por paises ricos, militares, para serem } \\
\text { usados em guerra }\end{array}$ & 0 & 0 & 1 & 1 & 1 \\
\hline alerta à humanidade & 1 & 0 & 0 & 1 & 1 \\
\hline através de um vírus & 0 & 0 & 1 & 1 & 1 \\
\hline não sabe & 3 & 4 & 16 & 23 & 30 \\
\hline em branco & 6 & 8 & 7 & 21 & 27 \\
\hline
\end{tabular}

* Houve mais de uma resposta para alguns sujeito. A porcentagem foi calculada pelo total da população pesquisada, isto é, 77 alunos $\left(21\right.$ da $1^{\text {a }}$ série, 26 da $2^{\text {a }}$ série e 30 da $3^{\mathrm{a}}$ série $)$

Após analise das unidades de pensamento expressos pelos escolares entrevistados, é que elaboramos, conjuntamente com eles e com os professores das instituições pesquisadas, o programa educativo, já descrito, atendendo as demandas emergenciais, com o apoio da família, da comunidade e dos multiprofissionais da Saúde e da Educação. Esse programa visou portanto, atender as necessidades dos escolares do local pesquisado, cujos temas foram trabalhados amplamente, com palestras, discussões e debates, oficinas pedagógicas através de vivências e dramatizações sobre os temas centrais, com fechamento e síntese dos temas pelos alunos e concluídas pelos profissionais habilitados, permitindo assim, um processo educativo efetivo de ensino e aprendizagem sobre as questões centrais.

As urnas espalhadas pelas escolas, por um tempo, para detecção de dúvidas ainda permanentes, surtiu efeito positivo. Destas emergiram outras dificuldades correlacionadas, que estão sendo programadas para realização de um novo evento, que deverá culminar com uma Feira de Exposições seguida de discussões e debates, sugerida por eles mesmos, onde pretende-se trabalhar abuso e assédio sexual, prostituição, homossexualidade, sexo seguro, parto, câncer de mama, relacionamento em grupo, drogas, entre outros.

\section{CONSIDERAÇÕES FINAIS E SUGESTÕES}

Depreendemos pois, que os jovens estudados têm um conceito de AIDS relativo, ligando-o, sobretudo, a sentimentos de fatalidade, ressaltando, assim, como prevenção, o uso da camisinha e revelando desconhecimento em relação a alguns aspectos do HIV/ AIDS, do seu corpo e do outro. Portanto, embora tendo 
informações, mesmo elementares, sobre sexualidade, o vírus e a doença, eles carecem de uma educação mais efetiva neste sentido, tendo em vista a necessidade da aquisição destes conhecimentos e habilidades, para a garantia da mudança de comportamento, visando assim a melhoria da qualidade de vida, tanto para si quanto para o outro, respeitando e compreendendo sua contextualidade global e resgate à cidadania, conforme referencial teórico preconizado pela OMS. Entendemos, ainda, ser a escola, o melhor local para se trabalhar estas questões. Para tanto, sugerimos que os enfermeiros dêem atenção especial a estas questões, voltando-se à saúde sexual e integral do escolar, levando-se em conta, orientações básicas sobre sexualidade humana, articulando também outros temas que se relacionam e fazem parte do dia a dia do aluno, considerando-se a faixa etária e o nível de complexidade dos temas a serem trabalhados.

\section{EDUCATIVE COMMUNICATION BETWEEN NURSES AND STUDENTS ABOUT STD/AIDS}

As school has been a crucial space for the development of knowledge and abilities in order to assure changes of behavior and considering the lack of reports about sexuality and STD/AIDS to the students, the present study aims to search scholars from three classes of high school, from a town surrounding the city of Ribeirão Preto - São Paulo. Authors identified students' problems by carrying out and assessing joint educative actions on the problems that have been found. Results have showed that these students relate AIDS to fatality and temerity and perhaps they are influenced by the message issued at the first decade of the history of this disearse while now, the tendency is to work with up to date knowledge and abilities. They form an opinion about AIDS as a sex and preventible disease. A it however, authors detected misinformation in another basic aspects. Therefore, we suggest nurses to work hard with this question.

\section{COMUNICACIÓN EDUCATIVA DEL ENFERMERO EN LA PROMOCIÓN DE LA SALUD SEXUAL PARA ESCOLARES: ETS-SIDA}

lA escuela es el espacio crucial para el desarrollo de conocimientos y habilidades para la garantizar cambios de comportamiento. Por existir carencia de informaciones a los alunnos sobre sexualidad y EST - HIV/SIDA, dificultando la resolución de sus problemas, buscamos investigar escolares de los $3^{\text {os }}$ años de escolaridad, de una ciudad próxima de Ribeirão Preto - SP. Intentamos identificar sus problemas, ejecutando y evaluando acciones educativas conjuntas acerca de los problemas encontrados. Los resultados evidenciaron que esos alunnos relacionan el SIDA a la fatalidad y temeridad, talves influenciados por los mensages emitidos en la $1^{a}$ década de la historia de la enfermedad, mientras hoy, la tendencia es trabajar conocimientos actualizados y habilidades direccionadas a la "no discriminación" de la sociedad y a la solidariedad, en razón de la existencia inminente del enfermolenfermedad en la sociedad. Conciben el SIDA como enfermedad de sexual prevenible, sin embargo revelan desinformación en otros aspectos básicos, justificandose la necesidad de acciones educativas. Por lo tanto, sugerimos que los enfermeros trabajen efectivamente esta cuestión.

TÉRMINOS CLAVES: comunicación en enfermería, educación para la salud, escolares x ETS - HIV/SIDA

\section{REFERÊNCIAS BIBLIOGRÁFICAS}

01. ASSOCIAÇÃO INTERDISCIPLINAR DA AIDS (ABIA). A AIDS e a escola. Rio de Janeiro, 1992, p. 9-44.

02. BUENO, S. M. V. Valorização da vida. Folha de São Paulo/ SP nordeste/ Folha Ribeirão. 23/03/96, Ribeirão Preto, cad.7, p. 7-2.

03. Semântica do binômio de saúde/ doença. São Paulo, 1993. 150 p. Tese (Doutorado) - Faculdade de Educação, Universidade de São Paulo.
04. CACERES, C. F. et al. Avaluating a school-based intervention for STD/AIDS prevention in Peru. Institute for Population Studies, Universidad Cayetano Heredia, Lima, Peru. Adolesc. Health.,v. 15, n.7, p. 582-91, Nov. 1994.

05. BRASIL. MINISTÉRIO DA SAÚDE (MS). Programa Nacional de DST-AIDS. Experiências que funcionam. Brasília, dez. 92 - fev. 93, p.107.

06. PIMENTEL, C. P. B. et al. Estudos de conhecimento de DST num grupo de adolescentes, da escola municipal de Florianópolis. Rev. Cienc. Saúde, v. 11, n. 2, p. 266-35, 1992. 
07. SCHONFELD, D. J. et al. A randomized, controled trial of a school-basead, multi-faceted AIDS education program in the elementary grades: the impact on compretension, knowledge and fears. Departament of Pediatries, Yale University School of Medicine, New Haven, USA. Pediatrics, v. 95, n. 4, p. 480-6, Apr. 1995.
08. SUNWOOD, J. et al. School-based AIDS education for adolescents. Office of the Associate Deanfor Student Affairs, Whashington University, St. Louis, Missouri, USA. Adolesc. Health, v. 16, n.4, p. 309-15, Apr. 1995. 


\section{AVALIAÇÃO DO PROGRAMA EDUCATIVO, REALIZADA PELOS ESCOLARES PESQUISADOS}

O que achou do programa

"achei excelente"; "foi muito bom"; "gostei muito"; "foi demais"; "foi uma oportunidade e tanto"; "adorei"; "foi maravilhoso esse evento"; "valeu muito"; "recebi muita informação importante, jamais pensei em aprender tanto"; "jamais vou esquecer"; etc.

O que você mais gostou

"tudo"; "a parte do sexo seguro"; "DST"; "AIDS"; "os teatros que fizemos do sexo, AIDS e drogas; as palestras foram muito boas e bem explicados os assuntos"; "o material distribuído ajudou muito"; "os cartazes foram ótimos"; etc.

O que você menos gostou

"não houve"; "saber como ficam as doenças do sexo"; "o tempo foi pouco"; "como tudo era importante, poderia ter mais tempo para discutir"; etc.

Quais as dúvidas que ainda permaneceram em você

"não houve"; "tudo foi bem trabalhado"; "discutimos bastante"; "agora vamos pensar melhor e depois vamos descobrindo as nossas dúvidas", etc.

Sugestões (tanto apresentadas no instrumento, quanto colhidas na urna)

"gostaríamos de falar mais sobre abuso sexual e assédio sexual/prostituição/homossexualidade/sexo seguro/ métodos anticoncepcionais/aborto/ masturbação/casamento, namoro, noivado/parto normal e cesárea/câncer de mama/como cuidar de recém nascido/ relacionamento em grupo/ficar/álcool, fumo e drogas, etc. 